Article

\title{
Croton cajucara Essential Oil Nanoemulsion and Its Antifungal Activities
}

\author{
Mariana M. B. Azevedo ${ }^{1, *}$, Catia A. Almeida ${ }^{1}$, Francisco C. M. Chaves ${ }^{2}$, Eduardo Ricci-Júnior ${ }^{3}$, \\ Andreza R. Garcia ${ }^{4}$, Igor A. Rodrigues ${ }^{4}\left(\mathbb{D}\right.$, Celuta S. Alviano ${ }^{1}\left(\mathbb{D}\right.$ and Daniela S. Alviano ${ }^{1, *(D)}$ \\ 1 Institute of Microbiology Paulo de Góes, General Microbiology Department, Federal University of Rio de \\ Janeiro (IMPG-UFRJ), CCS, Rio de Janeiro 21941-902, RJ, Brazil; catiamancio@yahoo.com.br (C.A.A.); \\ alviano@micro.ufrj.br (C.S.A.) \\ 2 EMBRAPA Western Amazon AM 10 Highway, Km 29, Manaus 69010-970, AM, Brazil; \\ celio.chaves@embrapa.br \\ 3 LADEG—Galenic Development Laboratory, School of Pharmacy, Federal University of Rio de Janeiro, CCS, \\ Rio de Janeiro 21941-590, RJ, Brazil; ricci@pharma.ufrj.br \\ 4 Department of Natural Products and Food, School of Pharmacy, Federal University of Rio de Janeiro, CCS, \\ Rio de Janeiro 21941-590, RJ, Brazil; deh.raposo@yahoo.com.br (A.R.G.); igor@pharma.ufrj.br (I.A.R.) \\ * Correspondence: maribarros@micro.ufri.br (M.M.B.A.); danialviano@micro.ufri.br (D.S.A.)
}

\section{check for}

updates

Citation: Azevedo, M.M.B.; Almeida C.A.; Chaves, F.C.M.; Ricci-Júnior, E.; Garcia, A.R.; Rodrigues, I.A.; Alviano, C.S.; Alviano, D.S. Croton cajucara Essential Oil Nanoemulsion and Its Antifungal Activities. Processes 2021, 9, 1872. https://doi.org/10.3390/pr 9111872

\section{Academic Editors:}

Greige-Gerges Helene and

Angela Scala

Received: 24 August 2021

Accepted: 9 October 2021

Published: 21 October 2021

Publisher's Note: MDPI stays neutral with regard to jurisdictional claims in published maps and institutional affiliations.

Copyright: (c) 2021 by the authors. Licensee MDPI, Basel, Switzerland. This article is an open access article distributed under the terms and conditions of the Creative Commons Attribution (CC BY) license (https:/ / creativecommons.org/licenses/by/ $4.0 /)$.

\begin{abstract}
The purpose of this study was to develop a stable nanoemulsion (NE) containing Croton cajucara 7-hydroxycalamenene-rich essential oil (NECC) with antifungal activity. The NECCs were prepared using an ultrasonic processor with Pluronic ${ }^{\circledR} \mathrm{F}-127$ as the aqueous phase. In order to evaluate the NECCs, the droplet size, polydispersity index (PdI), percentage of emulsification, and $\mathrm{pH}$ were determined along with a stability study. The NECC selected for the study had 15\% surfactant, showed $100 \%$ emulsification, Pdl of 0.249 , neutral $\mathrm{pH}$, droplet diameters of about $40 \mathrm{~nm}$, and remained stable over 150 days at room temperature. In addition, the NECC activity against some species of Zygomycetes and Candida, as well as the potential to inhibit fungal extracellular proteases, were assessed, and, finally, the hemolytic activity was evaluated. The best NECC antifungal activities were against Mucor ramosissimus (Minimal inhibitory concentration (MIC) $=12.2 \mu \mathrm{g} / \mathrm{mL}$ ) and Candida albicans $(\mathrm{MIC}=25.6 \mu \mathrm{g} / \mathrm{mL}$ ). The highest extracellular protease activities of $M$. ramosissimus and $C$. albicans were detected at $\mathrm{pH} 3$ and 4, respectively, which were totally inhibited after NECC treatment. The NECC showed no hemolytic effect at the highest concentration tested $(2 \mathrm{mg} / \mathrm{mL})$.
\end{abstract}

Keywords: nanoemulsion; Croton cajucara; essential oil; antifungal activity

\section{Introduction}

Nanoemulsions, unlike microemulsions, are metastable submicron oil-in-water dispersions with droplet diameters in the range of 10-100 nm, though they can also be described between 20 and $200 \mathrm{~nm}$. They are produced by high-energy methods such as ultrasound generators, high shear agitation, and high-pressure homogenizers. Potential advantages of nanoemulsions over conventional emulsions such as good physical stability, sterilization by filtration, high bioavailability, and low turbidity make them attractive systems for use in the food, cosmetics, and pharmaceutical industries. Nanoemulsions serve as delivery agents for lipophilic bioactive compounds, such as drugs, in the pharmaceutical industry, for flavors and antimicrobial agents in the food industry, for solubilizing water-insoluble pesticides in the agrochemical industry, and as a vehicle for skincare and personal products in cosmetics [1-3].

Nanoemulsions have several potential advantages over emulsions for encapsulating functional lipophilic components. The small size of the droplets in nanoemulsions significantly reduced the rate of destabilization mechanisms, such as gravitational separation, flocculation, and coalescence. Another potential advantage of using nanoemulsions is that the small droplet size means they are transparent or only slightly turbid [4]. 
Ultrasonic emulsification is a high-energy method to produce nanoemulsions and is well documented as a fast and efficient technique for formulating stable nanoemulsions with tiny droplet diameters and low polydispersity. The method applies sound waves with frequencies greater than $20 \mathrm{kHz}$ by using a sonotrode to cause mechanical vibrations followed by the formation of acoustic cavitation. The collapse of these cavities generates powerful shock waves that break the larger droplets. The size of the droplet diameters can be controlled by optimizing the process parameters such as oil concentration, emulsifier concentration, the mixing ratio of oil and surfactant, viscosity of continuous phase, emulsification time, and energy input [2].

Regarding the clinical use of nanoemulsion in the delivery of antimicrobial drugs, nanoemulsion formulations can be at oral and intravenous (IV) administrations. In addition, nanoemulsions can decrease the volatility of the drug, increase the time of the drug in the bloodstream, and improve its absorption by enterocytes [5].

Croton cajucara Benth. (Euphorbiaceae), popularly known as "sacaca", is a plant found in the Amazonian region with a safe history of use in folk medicine. Both the bark and the leaves of C. cajucara are popularly used in teas and pills to treat various diseases, including diabetes, diarrhea, stomachaches, fevers, hepatitis, and malaria. In addition, C. cajucara also presented anti-genotoxicity, anti-atherogenic, anti-tumor, antiulcerogenic, hypoglycemic, hypolipidemic, anti-estrogen, anti-inflammatory, and antinociceptive properties [6]. Two morphotypes of C. cajucara are known, white "sacaca" and red "sacaca", which are usually identified by the young leaf color and stems. In general, essential oils from the white morphotype are rich in linalool, while those from the red morphotype are rich in 7-hydroxycalamenene [7]. The essential oil of the leaves from the red morphotype and its major constituents were previously described to possess antibacterial, antifungal, and antileishmanial properties [7-10].

Mucormycosis (also known as zygomycosis) is a fungal infection caused by the Mucorales order fungi, which can be present in the soil and decaying organic matter, such as leaves, compost piles, and rotten wood. Mucormycosis is characterized by hyphal invasion of sinus tissue and a time course of less than 4 weeks. Uncontrolled diabetes mellitus and other forms of metabolic acidosis, corticosteroid treatment, organ or bone marrow transplantation, neutropenia, trauma and burns, malignant hematologic disorders, and deferoxamine therapy in hemodialysis patients are all major risk factors for mucormycosis. Therefore, new strategies to prevent and treat mucormycosis are needed, and such strategies can be aided by a thorough understanding of the disease's pathogenesis $[11,12]$.

Candida spp. can cause a wide range of pathologies of varying degrees depending on the pathogen and the host's immune condition. The colonization of the mucous membranes can occur by a change in the microbial population of the microbiota with a preponderant growth of Candida, which can then develop into a disseminated form. The deep infections result from dissemination that leads to a septic state that can evolve to multi-organ failure. Host risk factors associated with candidemia and invasive candidiasis are mainly related to neutropenia, prolonged hospitalization, the use of broad-spectrum antibiotics, chemotherapy, mucosal colonization, vascular catheters, parenteral nutrition, major surgery (mainly the gastrointestinal tract), and renal failure. In addition, some patients have a higher risk of developing candidemia due to their underlying medical conditions before admission as transplant recipients, diabetics, and elderly patients [13].

The aspartic proteases (E.C.3.4.23), also named acid proteases, are a group of endopeptidases with aspartic acid residues at their active site. Aspartic proteases that are excreted are called secreted aspartic proteases (sap's). The main functions of sap's are their use as microbial coagulants in cheese making in substitution of calf rennet, plant invasion of phytopathogens, and fungal invasion in infection of the human host (e.g., zygomycosis and candidemia). The sap's aid in the colonization and penetration of tissues in zygomycosis and candidemia [14].

This study investigated the potential of using the C. cajucara essential oil release system for its antifungal activity. Nanoemulsions were developed and evaluated in terms of the 
emulsification percentage, droplet size, polydispersion index, $\mathrm{pH}$, stability, and morphology by transmission electron microscopy, and their antifungal activity was determined.

\section{Materials and Methods}

\subsection{Plant Material and Essential Oil Extraction}

Plant material from C. cajucara was obtained from the EMBRAPA Experimental Farm, Amazonas, Brazil. A voucher specimen was deposited at EMBRAPA Amazonia Oriental Herbarium (registry IAN 165013). Leaves of C. cajucara were collected between 8 and 9 a.m., dried at room temperature, and coarsely ground into powder just before distillation. The oil was obtained by hydrodistillation in a modified Clevenger apparatus over a $5 \mathrm{~h}$ period [7].

\subsection{Essential Oil Analysis}

C. cajucara essential oil (SO, sacaca oil) was analyzed in an Agilent $6890 \mathrm{~N}$ gas chromatograph fitted with a 5\%-diphenyl-95\%-dimethylpolysiloxane capillary column (HP-5, $25 \mathrm{~m} \times 0.32 \mathrm{~mm} \times 0.25 \mu \mathrm{m}$ ). Mass spectra were obtained with an Agilent $5973 \mathrm{~N}$ system, according to Pereira et al. (2011). The results were compared with data from the literature $[15,16]$.

\subsection{Oil-in-Water Nanoemulsion Preparation}

Different NEs containing SO, as the oily phase, and Pluronic ${ }^{\circledR}$ F-127, as the aqueous phase, were produced. The amount of surfactant in the aqueous phase was prepared in three concentrations: $10 \%, 12.5 \%$, and $15 \%$. The optimal surfactant concentration was $15 \%$, as it remained in the liquid state, and the amount of essential oil was 5\% (Table S1, Supplementary Material). NEs were produced using, first, a Vortex ${ }^{\circledR}\left(\mathrm{KASVI}^{\circledR}\right.$ model K401010) for $1 \mathrm{~min}$ for homogenization and then, second, an ultrasonic processor (UP100H, Hielscher ${ }^{\circledR}$ ) with 100 watts and $30 \mathrm{kHz}$, in cycle 1 . Samples were sonicated under an ice bath at $5{ }^{\circ} \mathrm{C}$. After production, they were tested for storage stability in an incubator at $37^{\circ} \mathrm{C}$, room temperature at $25^{\circ} \mathrm{C}$, and in a refrigerator at $3^{\circ} \mathrm{C}$ [17].

\subsection{Particle Mean Size and Size Distribution}

The mean size of the NEs droplets (diameter in $\mathrm{nm}$ ) was determined by the dynamic light scattering (DLS) technique using a Zetasizer, Nano ${ }^{\circledR} \mathrm{S} 90$ (Malvern Instruments ${ }^{\circledR}$ ), with optics of $90^{\circ}$ scattering detector angle, at room temperature $\left(25^{\circ} \mathrm{C}\right)$. Transmission electron microscopy was also performed to visualize the structure of the NEs and confirm their size. The NEs were diluted 1:50 in distilled water for these analyses, and the measurements were performed at room temperature $\left(25^{\circ} \mathrm{C}\right)$. DLS was used to screen the preparations, in which the smaller size and lower polydispersity index (PdI) were selected. Analyzes were performed in triplicate, and the results are expressed as the mean \pm standard deviation [17].

\subsection{Percentage of Essential Oil Emulsification}

The percentage of essential oil emulsification was obtained spectrophotometrically (SpectraMax M5/Molecular Devices) by making a standard curve of the C. cajucara essential oil and comparing it with ultrasonicated Pluronic ${ }^{\circledR}$ F-127 and the NEs. The percentage of essential oil in nanoemulsion was obtained through logarithmic regression.

\subsection{Kinetics Stability}

Kinetic stability tests were performed after 7 days of storage of the NEs at room temperature $\left(25^{\circ} \mathrm{C}\right)$ and repeated after $30,60,90,120$, and 150 days in storage and evaluated by the percentage of emulsification. 


\subsection{Hydrogenionic Potential $(p H)$}

The hydrogenionic potential $(\mathrm{pH})$ was measured using the Bante Instrument potentiometer model 922. The readings were performed in fresh and 150-storage-day samples, at room temperature $\left(25^{\circ} \mathrm{C}\right)$ and at the kinetic stability times.

\subsection{Antifungal Activity Assay of Nanoemulsion of Croton cajucara (NECC)}

The antifungal activity of nanoemulsions containing essential oil of $C$. cajucara red morphotype was evaluated against Absidia cylindrospora (URM4476), Cuninghamella elegans (URM2084), Mucor circinelloides (LIKA0066), M. mucedo (LIKA0072), M. ramosissimus (URM3087), Rhizopus microsporus (LMC123), R. oryzae (UCP1506), and Syncephalastrum racemosum (UCP1550), as well as C. albicans (ATCC 10231), C. albicans serotype A (ATCC 36801), and C. albicans serotype B (ATCC 36802). Emulsions without the essential oil of C. cajucara were also tested as an antifungal activity control. In addition, the purified 7-hydroxycalamenene (7-OH) obtained elsewhere [7] was also tested, and its antifungal minimal inhibitory concentrations (MICs) could be compared with the results obtained for the essential oil of $C$. cajucara nanoemulsions.

The microdilution broth methods were used according to CLSI reference documents M27-A2 [18] for yeasts and M38-A2 [19] for filamentous fungi. Positive and negative growth controls and blanks were made. The antifungal activities of sonicated Pluronic at nanoemulsion concentration were also made and showed no activity to any fungi. All experiments were performed in duplicate and repeated twice. The nanoemulsion was diluted 1:1 in RPMI broth, and an aliquot of $100 \mu \mathrm{L}$ was placed in the first well of the microplate to initiating serial dilution.

To evaluate the fungicide/fungistatic properties of C. cajucara essential oil nanoemulsion, a $10 \mu \mathrm{L}$ aliquot of serial dilutions was dropped on the surface of potato dextrose agar and incubated at $37^{\circ} \mathrm{C}$ for $72 \mathrm{~h}$ or Sabouraud agar and incubated at $37^{\circ} \mathrm{C}$ for $48 \mathrm{~h}$. If growth is observed, the nanoemulsion activity is fungistatic; if not, it is fungicidal.

\subsection{Activity of Extracellular Proteases}

In order to evaluate a possible mode of action of NECC, the supernatants of fungi grown in RPMI at MIC conditions were collected and filtered by sterile Millipore $(0.22 \mu \mathrm{m})$. The supernatants enzymatic activities were determined according to Almeida et al. (2018) [20] with some modifications. First, $20 \mu \mathrm{L}$ of the supernatant was added to $20 \mu \mathrm{L}$ BSA $(1 \mathrm{mg} / \mathrm{mL})$ and $60 \mu \mathrm{L}$ buffer ( $\mathrm{pH} 1.0-11.0$ ) onto a 96-well plate. Then, after $1 \mathrm{~h}$ of incubation at $37^{\circ} \mathrm{C}$, $100 \mu \mathrm{L}$ of Bradford solution (0.025\% Coomassie Blue G-250, 11.75\% ethanol, and 21.25\% phosphoric acid) was previously diluted (1:1) and added. Negative control was prepared by adding the substrate immediately after the incubation period. Finally, the plate was read on a spectrophotometer (SpectraMax M5) at $595 \mathrm{~nm}$. One unit of enzyme activity was defined as the total enzyme that causes an increase of 0.001 in absorbance unit under the standard assay conditions.

Alternatively, the supernatants were pre-incubated for $20 \mathrm{~min}$ at $37^{\circ} \mathrm{C}$ in the presence or absence of pepstatin A (10 mM) and NECC (in the minimum inhibitory concentration). In the latter case, the results are expressed as a relative percentage of activity.

\subsection{Hemolytic Activity}

Cytotoxicity against erythrocytes was determined by the spectrophotometric assay [21]. Human blood samples $(\mathrm{O}+)$ were collected from a healthy volunteer into $\mathrm{BD}^{\mathrm{TM}}$ Vacutainer ${ }^{\mathrm{TM}}$ Citrate tubes. The blood samples were centrifuged ( $\left.2000 \mathrm{rpm} / 5 \mathrm{~min}\right)$, washed three times with phosphate buffer saline (PBS, pH 7.2), and a final cellular suspension was prepared ( $4 \%$, in PBS). Aliquots of $80 \mu \mathrm{L}$ were distributed into 96-well microplates, where $20 \mu \mathrm{L}$ of different concentrations $(0.03$ to $2 \mathrm{mg} / \mathrm{mL}$ ) of NECC were previously deposited. Emulsions without the essential oil of $C$. cajucara were also tested as a hemolytic activity control. After $1 \mathrm{~h}$ at $37^{\circ} \mathrm{C}$, the reaction was slowed down by adding $200 \mu \mathrm{L}$ of PBS or distilled water (positive control for 100\% hemolysis). Next, the microplates were centrifuged, 
and the supernatant was collected for spectrophotometric analysis at $540 \mathrm{mn}$ (SpectraMax M5, Molecular Devices, CA, USA). Three independent experiments were performed, and the results were expressed as a percentage of hemoglobin released by treated cells relative to the positive control. The blood collection procedures were approved by the Institutional Ethics Board (CAAE 35524814.4.0000.0107). In addition, the informed consent form was duly signed by the volunteer.

\section{Results and Discussion}

GC-MS of the essential oil from C. cajucara showed that it is rich in 7-hydroxycalamenene (Table 1), the expected major constituent of the red morphotype, which has been previously described as responsible for its antimicrobial activities [7-10].

Table 1. Composition of C. cajucara essential oil used in the nanoemulsion formulation.

\begin{tabular}{|c|c|c|c|}
\hline Peak & LRI * & Area \% & Identification \\
\hline 1 & 1459 & 2.32 & aromadendrene $<$ allo $>$ \\
\hline 2 & 1480 & 2.43 & germacrene D \\
\hline 3 & 1494 & 1.14 & bicyclogermacrene \\
\hline 4 & 1498 & 3.3 & $\alpha$-muurolene \\
\hline 5 & 1513 & 6.77 & $\gamma$-cadinene \\
\hline 6 & 1522 & 11.01 & $\delta$-cadinene \\
\hline 7 & 1554 & 6.1 & germacrene B \\
\hline 8 & 1575 & 1.08 & spathulenol \\
\hline 9 & 1580 & 5.48 & caryophyllene oxide \\
\hline 10 & 1626 & 2.34 & dill apiole \\
\hline 11 & 1640 & 5.86 & $\tau$-cadinol \\
\hline 12 & 1652 & 1.47 & $\alpha$-cadinol \\
\hline 13 & 1803 & 50.63 & 7-hydroxycalamenene \\
\hline \multicolumn{2}{|c|}{ Total } & & 99.93 \\
\hline
\end{tabular}

${ }^{*}$ Linear retention index.

The nanoemulsion formulations were prepared with Pluronic ${ }^{\circledR}$ F-127 at concentrations of $10 \%, 12.5 \%$, and $15 \%$. The concentration chosen was the one that remained in the liquid state, which was $15 \%$, the temperature that kept NECC stable was room temperature at $25^{\circ} \mathrm{C}$, and the concentration of 7-hydroxycalamenene in the nanoemulsion obtained was $52.63 \mathrm{mg} / \mathrm{mL}$. The average PdI obtained for the formulation was $0.249 \pm 0.014$, showing that NECC is monodisperse, indicating size homogeneity. The average size was $45.56 \pm 15.76 \mathrm{~nm}$, obtained by the Z-average size parameter of the equipment report.

Using the graph in Figure 1, it was possible to calculate the percentage of essential oil emulsification based on the logarithmic regression equation. The value encountered was $100 \%$.

Figure 2A shows that the size distribution remained within the expected limits of the kinetic stability test. In addition, the evaluation of its shelf-life test showed at least 5 months of size stability. 


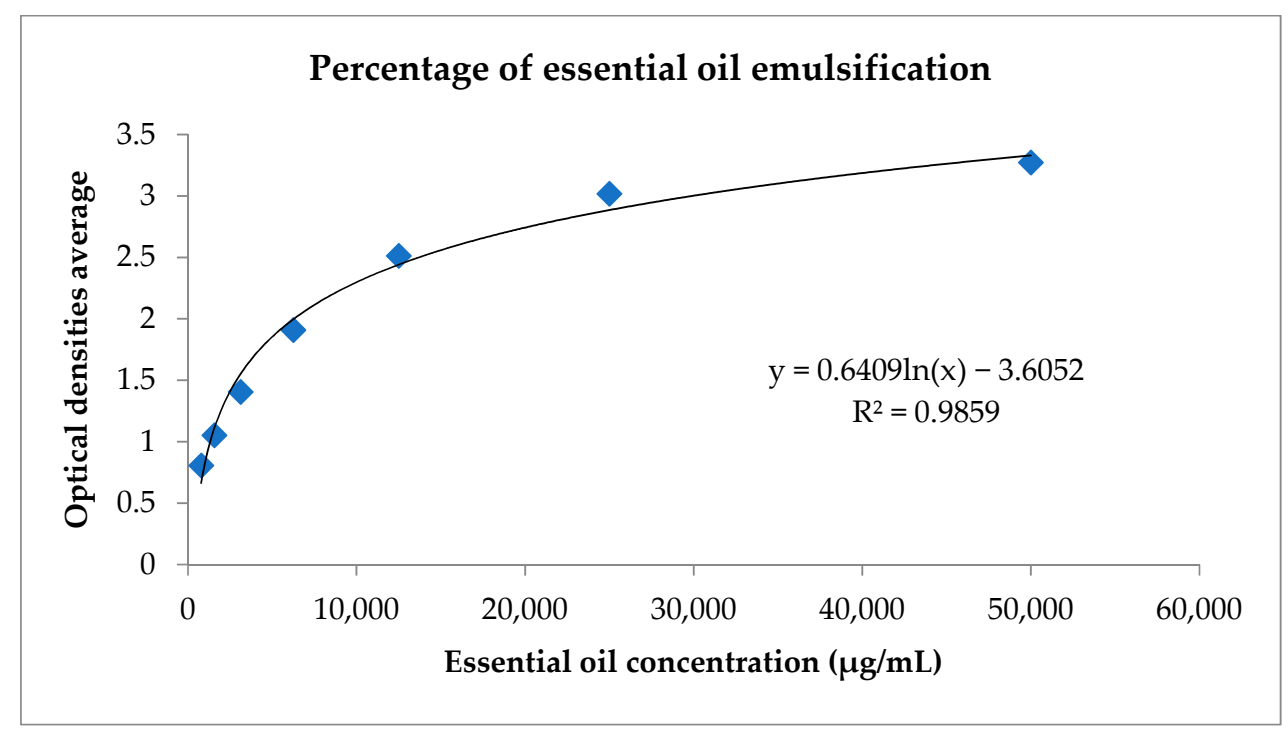

Figure 1. Logarithmic regression to calculate the percentage of emulsification of C. cajucara essential oil. Standard curve of the C. cajucara essential oil compared with ultrasonicated Pluronic ${ }^{\circledR}$ F-127 and the NEs. The percentage of essential oil in nanoemulsion was based on the equation obtained through logarithmic regression.

Most patients with rhinocerebral zygomycosis have problems with $\mathrm{pH}$ due to diabetic ketoacidosis. In systemic acidosis, the iron of proteins is released to the serum, and these two conditions promote the growth of zygomycetes spreading the infection [22]. Therefore, medicines with a neutral or slightly basic $\mathrm{pH}$ can help fight infection and help with tissue repair. Thus, the $\mathrm{pH}$ of 7.3-8.3 (Figure $2 \mathrm{~B}$ ) obtained by the formulation at the stability study kept at room temperature $\left(25^{\circ} \mathrm{C}\right)$ was considered suitable for human testing.

The NEs were observed by transmission electron microscopy (Figure 3), and a droplet size of about $40 \mathrm{~nm}$ measured by DLS was confirmed. The NECCs are spherical, and the shape is regular, as described by de Siqueira et al. 2019 [17]. Arrows indicate small oil drops. Some drops are isolated, and others are agglomerated. This is because TEM requires the removal of the aqueous phase causing agglomeration of the oil droplets of the nanoemulsion. In the clusters of drops, the light parts are oil drops, and the dark parts are the fused surfactant layers. In isolated drops, the light part is the oil drop, and the dark part is the surfactant layer.

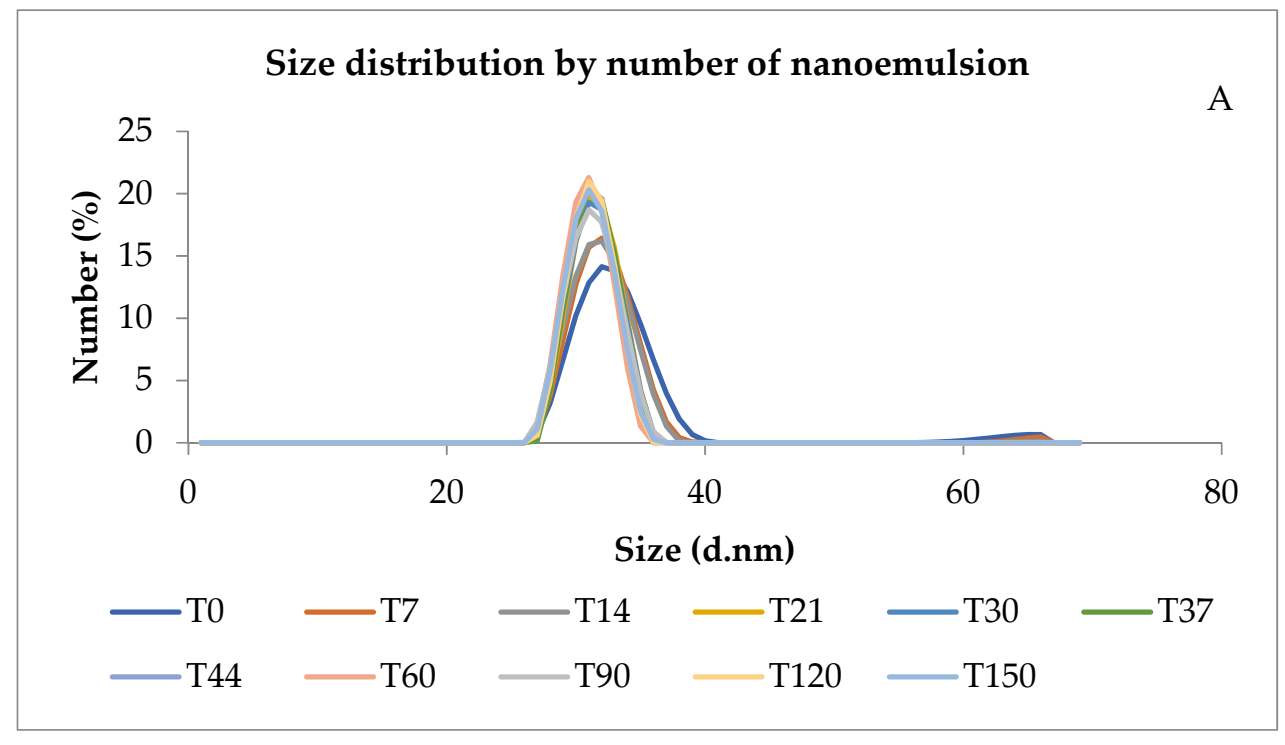

Figure 2. Cont. 


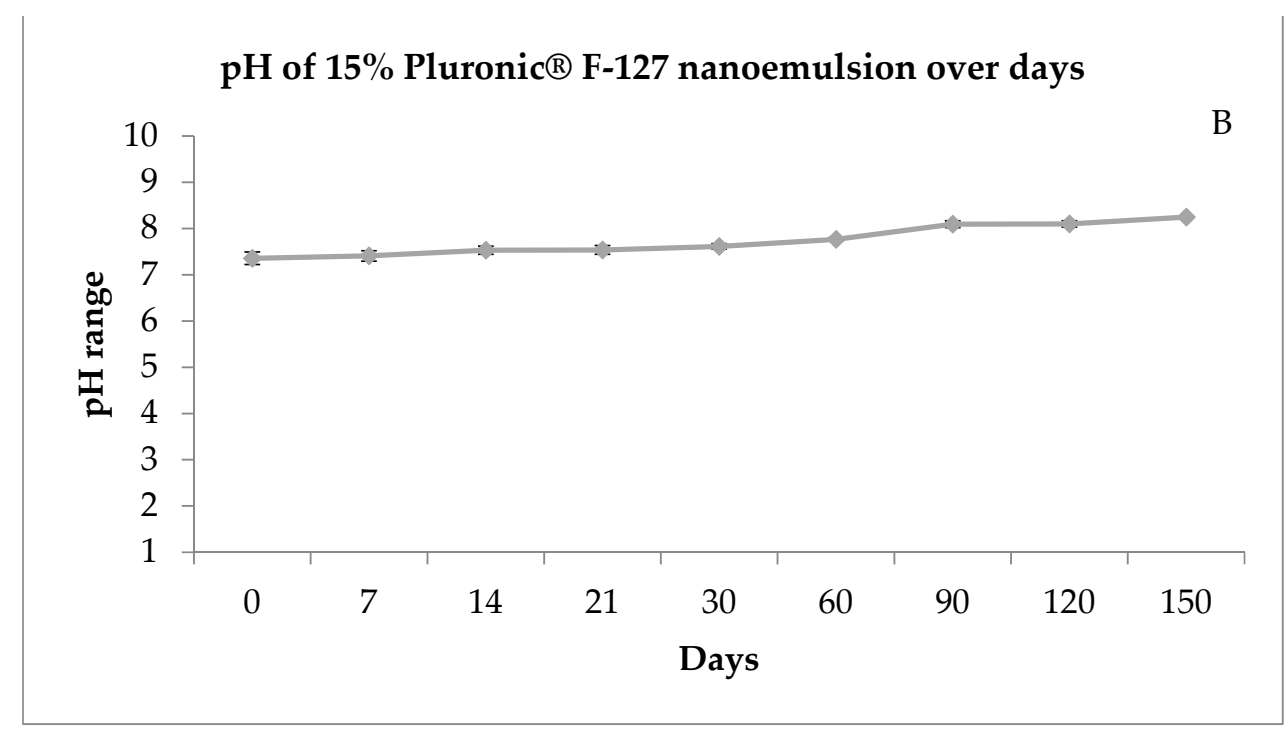

Figure 2. Size distribution of nanoemulsion by number (A) and $\mathrm{pH}$ of the nanoemulsion prepared with $15 \%$ of Pluronic ${ }^{\circledR}$ F-127 over days (B). T = time in days.

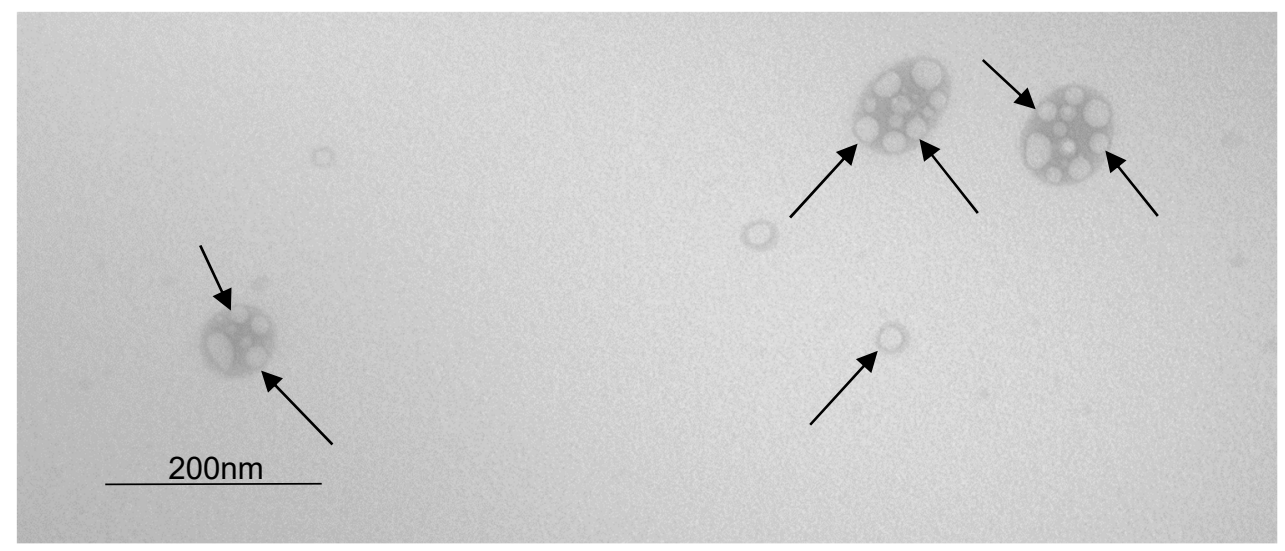

Figure 3. Transmission electron microscopy of NECCs (black arrows) at $71,000 \times$ of magnification and $80 \mathrm{kV}$ of accelerating voltage.

The evaluation of NECC activity in inhibiting the microbial growth of microorganisms of medical importance was promising, as can be seen in Table 2. Emulsions without the essential oil of $C$. cajucara were also tested as a control, and no inhibitory activities were detected in all fungi tested.

The Euphorbiaceae family has several species with biological activities as antifungal [23], biolarvicidal and pupicidal [24], antioxidant and anticancer [25], and antibacterial [26]. Our research group has previously described the antifungal [7-9,27], antibacterial [9], antileishmania [10], and antioxidant [9] activities of Croton cajucara essential oil.

The MIC assays show that the zygomycetes species tested are very sensitive to NECC and the most promising activities were against Absidia cylindospora, Mucor ramosissimus, and Syncephalastrum racemosum, all common agents of zygomycosis. However, NECC improved the essential oil activity against $M$. ramosissimus and S. racemosum, while the nonemulsified essential oil was not effective against these fungi. All Candida albicans strains tested were susceptible to NECC. According to Azevedo et al. (2014) [7], zygomycetes were shown to be sensitive to 7-hydroxycalamenene because this substance affected these fungi respiratory chain and spores germination. Azevedo et al. (2016) [27] showed that 7-hydroxycalamenene also demonstrated intense activity against some strains of $C$. albicans, 
and their proteases were also inhibited. Different authors showed other relevant activities as inhibition of lipidic peroxidation [28], leishmanicidal [10], and therapeutic potential for Alzheimer's disease [29].

Table 2. Minimal inhibitory concentration (MIC) of NECC and 7-hydroxycalamenene (7-OH).

\begin{tabular}{|c|c|c|c|c|}
\hline \multirow[b]{2}{*}{ Microorganisms } & \multicolumn{2}{|c|}{ NECC } & \multicolumn{2}{|c|}{ 7-OH } \\
\hline & MIC ( $\mu \mathrm{g} / \mathrm{mL})$ & Effect & MIC ( $\mu \mathrm{g} / \mathrm{mL})$ & Effect $^{1}$ \\
\hline \multicolumn{5}{|l|}{ Filamentous fungi } \\
\hline Absidia cylindospora (URM4476) & 12.21 & Static & 19.53 & Static \\
\hline Cuninghamella elegans (URM 2084) & 24.41 & Static & 19.53 & Static \\
\hline Mucor circinelloides (LIKA0066) & 48.83 & Static & 19.53 & Cide \\
\hline M. mucedo (LIKA 0072) & 48.83 & Static & 2500 & Static \\
\hline M. ramosissimus (URM 3087) & 12.21 & Static & 2500 & Static \\
\hline Rhizopus microsporus (LMC123) & 195.31 & Static & 19.53 & Static \\
\hline R. oryzae (UCP 1506) & 97.66 & Static & 39.06 & Static \\
\hline $\begin{array}{c}\text { Syncephalastrum racemosum } \\
\text { (UCP1550) }\end{array}$ & 12.21 & Static & 2500 & Static \\
\hline \multicolumn{5}{|l|}{ Yeasts } \\
\hline Candida albicans (ATCC 10231) & 25.69 & Static & 39.06 & Static \\
\hline C. albicans serotype A (ATCC 36801) & 25.69 & Static & 39.06 & Static \\
\hline C. albicans serotype B (ATCC 36802) & 51.39 & Static & 78.12 & Static \\
\hline
\end{tabular}

${ }^{1}$ Cide $=$ fungicide; Static $=$ fungistatic .

Through the growth curve, it is possible to observe the growth over time. Figure 4 shows the interference of NECC on growth.

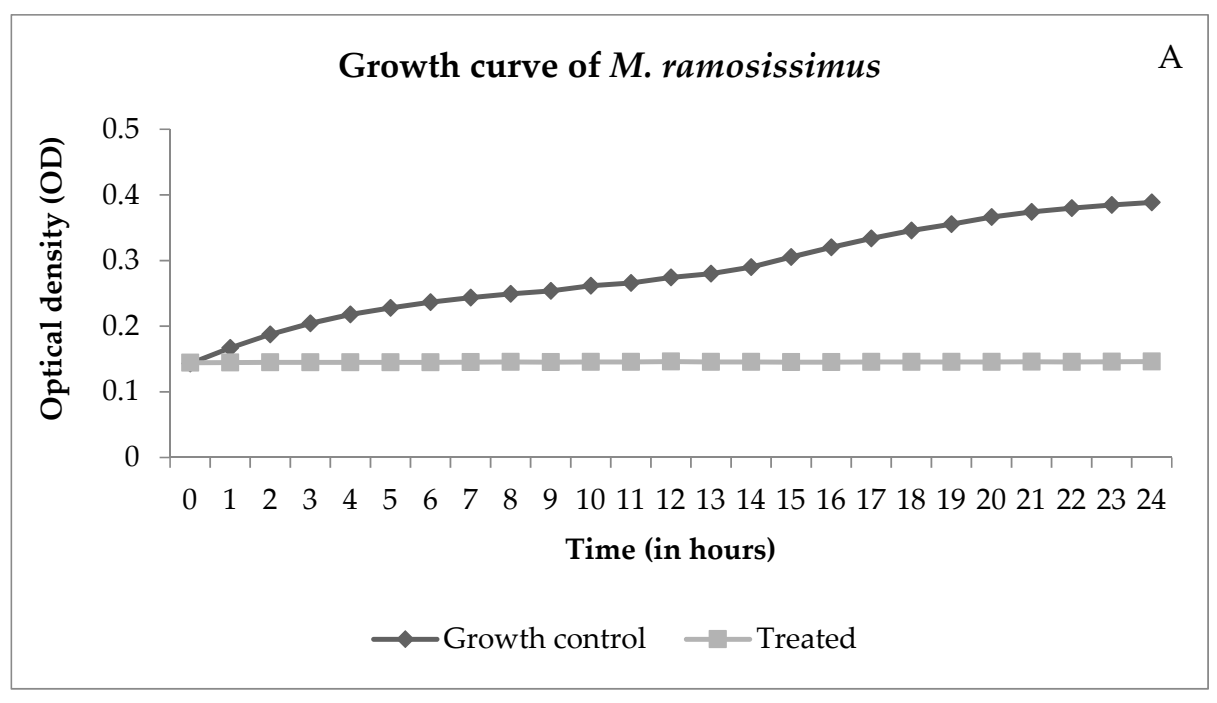

Figure 4. Cont. 


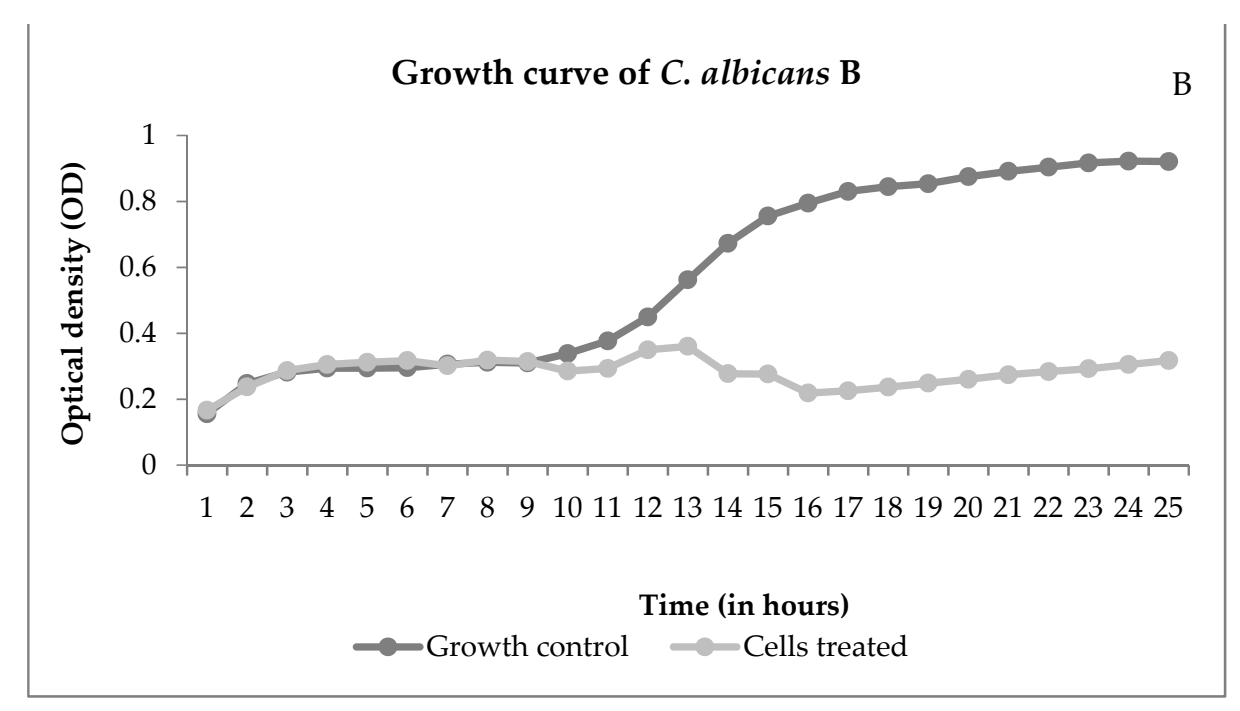

Figure 4. Growth curves of Mucor ramosissimus (A) and Candida albicans B (B), controls, and cells treated with NECC at MIC and room temperature $\left(25^{\circ} \mathrm{C}\right)$.

Figure $4 \mathrm{~A}$ shows that $M$. ramosissimus did not differentiate with treatment with NECC at MIC, and C. albicans kept the differentiation until the 9th hour, and then it stopped. In both cases, the microorganisms were not killed, showing that the activity of NECC is fungistatic. Recently, with the COVID-19 pandemic, the incidence of zygomycosis, colloquially called "black fungus", has increased. Spore germination occurs due to various reasons such as low oxygen saturation, high iron levels as evidenced by high ferritin, immunosuppression caused by SARS-CoV-2, decreased phagocytic activity of white blood cells, and hyperglycemia from corticosteroid use [30]. These are all conditions for the development of zygomycosis and candidiasis. Candidiasis is another fungal infection associated with COVID-19. In addition to the factors described, intubation is a risk factor that predisposes the patient to colonization and pulmonary proliferation of Candida species [31]. Thus, the development of natural substances with promising antimicrobial activity and low toxicity is of great importance in order to improve patient survival.

The greatest proteases activities for M. ramosissimus occurred at $\mathrm{pH}$ (Figure 5A) and for C. albicans at pH4 (Figure 5B). Thus, the following experiment evaluated whether NECC inhibits proteases activities at $\mathrm{pH} 3$ (M. ramosissimus) and $\mathrm{pH} 4$ (C. albicans). The aspartic proteases activities of both fungi were completely inhibited when treated with MIC concentrations of NECC (Figure 5C). The inhibition of aspartic proteases activity could be an important way to control these fungi [32]. According to Morace and Borghi (2012) [33], Mucorales of the genus Mucor are the second cause of invasive mucormycosis. Challa (2019) [34] stated that aspartic proteases of Mucorales favor host invasion. Azevedo (2014) [7] demonstrated that 7-hydroxycalamenene showed inhibitory activity against rhizopuspepsin (pepsin present in the main genus of zygomycosis, Rhizopus). It is also well known that C. albicans produces various types of secreted aspartic proteases (Saps), and the production of these Saps varies according to their shape (yeast cells or hyphal form), the $\mathrm{pH}$, and the available substrate. Saps can also hydrolyze various substrates such as keratin, collagen, laminin, fibronectin, salivary lactoferrin, and others [32]. Therefore, the results shown in Figure 5 are promising, as they inhibited 100\% of the Mucor and Candida proteases. These results show that 7-hydroxycalamenene appears to be efficient in inhibiting an important Zygomycetes and Blastomycetes mechanism of action. 

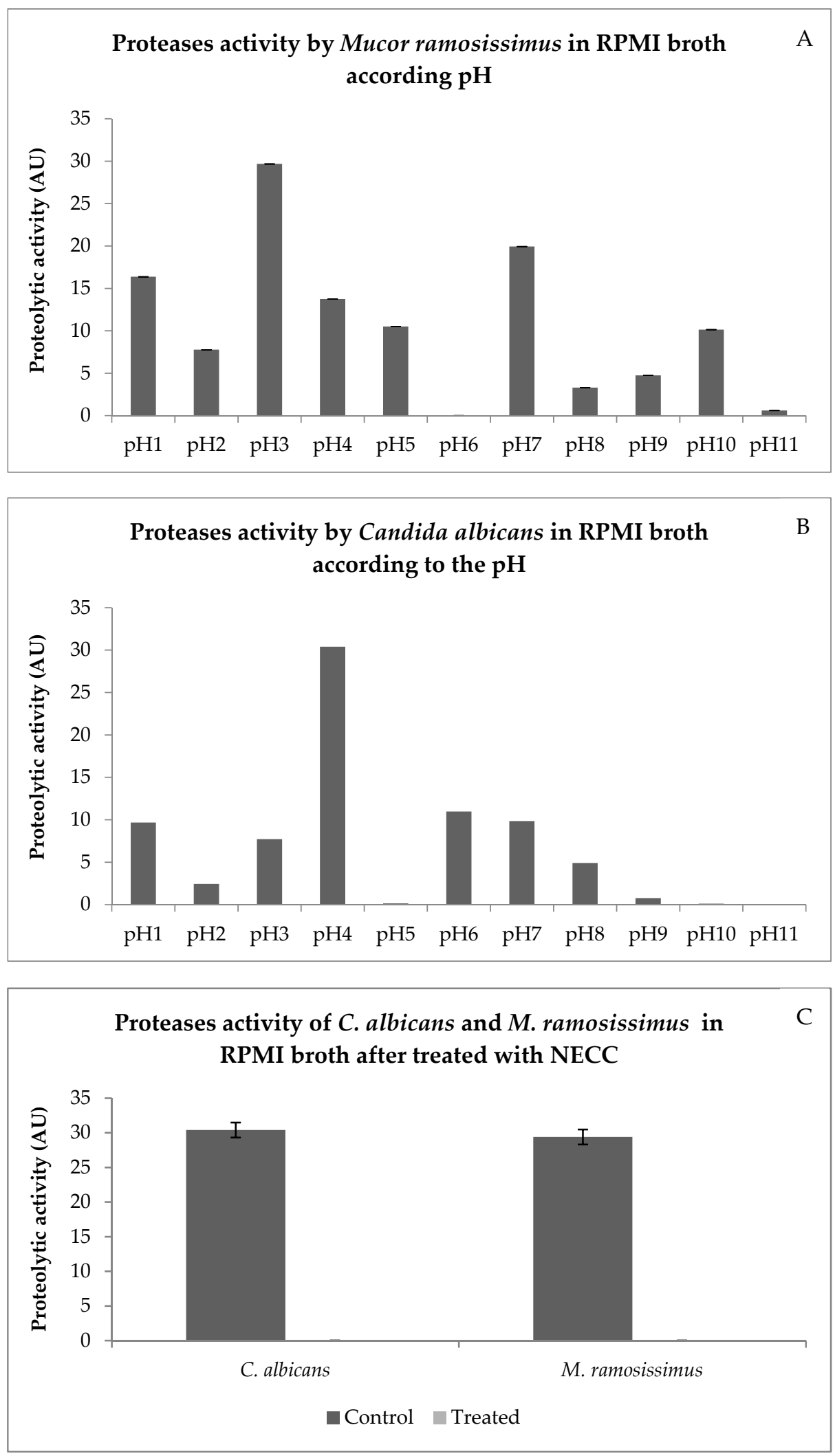

Figure 5. Proteases activity by M. ramosissimus (A), C. albicans (B) in RPMI broth according to the pH. Proteases activities by C. albicans and M. ramosissimus in RPMI broth after treatment with NECC (in arbitrary unit-AU) (C).

In addition, NECC demonstrated no hemolytic effect even at the highest concentration tested (2 mg/mL). According to Rodrigues et al. (2013) [10], 7-hydroxycalamenene, which 
was the main component of the essential oil that they used in their study $(>50 \%)$, was shown to be non-toxic to peritoneal mouse macrophages at a concentration of $500 \mu \mathrm{g} / \mathrm{mL}$.

\section{Conclusions}

In this study, a nanoemulsion was obtained with a $100 \%$ emulsification percentage and was stable for more than 150 days at room temperature $\left(25^{\circ} \mathrm{C}\right)$, with a droplet size of around $40 \mathrm{~nm}$. This formulation proved to be effective against zygomycetes, especially against the Mucor ramosissimus and Candida albicans strains tested. In addition, the nanoemulsion inhibited $100 \%$ of their extracellular protease activity. NECC also demonstrated no hemolytic effect at a maximum concentration of $2 \mathrm{mg} / \mathrm{mL}$.

According to the results presented, in vivo experiments should be conducted to confirm the promising activities of the proposed nanoemulsion. However, nanoemulsions containing essential oils can be a way to improve antifungal activities and be widely used as we live in times of resistant microorganisms.

Supplementary Materials: The following are available online at https://www.mdpi.com/article/ 10.3390/pr9111872/s1, Table S1: NEs formulation optimization. Different NEs were produced containing SO (1 and 5\%) as the oily phase and Pluronic ${ }^{\circledR} \mathrm{F}-127(10 \%, 12.5 \%$, and $15 \%)$ as the aqueous phase.

Author Contributions: Conceptualization, M.M.B.A.; C.A.A.; C.S.A. and D.S.A., methodology, M.M.B.A.; C.A.A.; F.C.M.C.; E.R.-J; A.R.G.; and I.A.R.; formal analysis, M.M.B.A.; C.A.A.; E.R.-J.; C.S.A. and D.S.A.; investigation and data curation, M.M.B.A.; C.A.A.; F.C.M.C.; E.R.-J; A.R.G.; I.A.R.; C.S.A. and D.S.A.; writing-original draft preparation, M.M.B.A.; writing-review and editing, C.A.A.; F.C.M.C.; E.R.-J.; A.R.G.; I.A.R.; C.S.A. and D.S.A.; supervision, C.S.A.; D.S.A.; project administration, C.S.A.; D.S.A.; funding acquisition, C.S.A.; D.S.A. All authors have read and agreed to the published version of the manuscript.

Funding: This study was supported by Fundação Carlos Chagas Filho de Amparo a Pesquisa do Estado do Rio de Janeiro (FAPERJ) grant number E-26/203.035/2017 (233939), Coordenação de Aperfeiçoamento de Pessoal de Nível Superior (CAPES) and Conselho Nacional de Desenvolvimento Científico e Tecnológico (CNPq).

Acknowledgments: The authors thank Maria Barbara Faria Cardoso da Silva for technical assistance and sample preparation. This study was supported by Fundação Carlos Chagas Filho de Amparo a Pesquisa do Estado do Rio de Janeiro (FAPERJ), Coordenação de Aperfeiçoamento de Pessoal de Nível Superior (CAPES) and Conselho Nacional de Desenvolvimento Científico e Tecnológico (CNPq).

Conflicts of Interest: The authors declare no conflict of interest. The funders had no role in the design of the study, in the collection, analyses, or interpretation of data, in the writing of the manuscript, or in the decision to publish the results.

\section{References}

1. Sonneville-Aubrun, O.; Simonnet, J.T.; L'alloret, F. Nanoemulsions: A new vehicle for skincare products. Adv. Colloid Interface Sci. 2004, 108, 145-149. [CrossRef]

2. Ghosh, V.; Mukherjee, A.; Chandrasekaran, N. Ultrasonic emulsification of food-grade nanoemulsion formulation and evaluation of its bactericidal activity. Ultrason. Sonochem. 2013, 20, 338-344. [CrossRef]

3. Rodrigues, I.A.; Ramos, A.D.S.; Falcão, D.Q.; Ferreira, J.L.P.; Basso, S.L.; Silva, J.R.D.A.; Amaral, A.C.F. Development of nanoemulsions to enhance the antileishmanial activity of Copaifera paupera oleoresins. Biomed Res. Int. 2018, 2018, 9781724. [CrossRef]

4. Chang, Y.; McLandsborough, L.; McClements, D.J. Physical properties and antimicrobial efficacy of thyme oil nanoemulsions: Influence of ripening inhibitors. J. Agric. Food Chem. 2012, 60, 12056-12063. [CrossRef]

5. Fast, J.P.; Mecozzi, S. Nanoemulsions for intravenous drug delivery. In Nanotechnology in Drug Delivery; Springer: New York, NY, USA, 2009; pp. 461-489.

6. Lima, G.S.; Castro-Pinto, D.B.; Machado, G.C.; Maciel, M.A.; Echevarria, A. Antileishmanial activity and trypanothione reductase effects of terpenes from the Amazonian species Croton cajucara Benth (Euphorbiaceae). Phytomedicine 2015, 22, 1133-1137. [CrossRef] [PubMed] 
7. Azevedo, M.M.; Almeida, C.A.; Chaves, F.C.; Campos-Takaki, G.M.; Rozental, S.; Bizzo, H.R.; Alviano, C.S.; Alviano, D.S. Effects of 7-Hydroxycalamenene Isolated from Croton cajucara Essential Oil on Growth, Lipid Content and Ultrastructural Aspects of Rhizopus oryzae. Planta Med. 2014, 80, 550-556. [CrossRef]

8. Azevedo, M.M.; Pereira, A.Q.; Chaves, F.C.; Bizzo, H.R.; Alviano, C.S.; Alviano, D.S. Antimicrobial activity of the essential oils from the leaves of two morphotypes of Croton cajucara Benth. J. Essent. Oil Res. 2012, 24, 351-357. [CrossRef]

9. Azevedo, M.; Chaves, F.; Almeida, C.A.; Bizzo, H.R.; Duarte, R.S.; Campos-Takaki, G.M.; Alviano, C.S.; Alviano, D.S. Antioxidant and antimicrobial activities of 7-hydroxy-calamenene-rich essential oils from Croton cajucara Benth. Molecules 2013, 18, $1128-1137$. [CrossRef] [PubMed]

10. Rodrigues, I.A.; Azevedo, M.M.; Chaves, F.C.; Bizzo, H.R.; Corte-Real, S.; Alviano, D.S.; Alviano, C.S.; Rosa, M.S.S.; Vermelho, A.B. In vitro cytocidal effects of the essential oil from Croton cajucara (red sacaca) and its major constituent 7-hydroxycalamenene against Leishmania chagasi. BMC Complement. Altern. Med. 2013, 13, 249. [CrossRef]

11. Tewari, S.; David, J.; Nakhale, S.; David, B. Mucormycosis: Post COVID-19 Fungal Infection. Int. J. Curr. Microbiol. Appl. Sci. 2021, 10, 64-71.

12. Patil, S.; Sarate, D.; Chopade, S.; Khade, M.; Dhage, S.; Kangate, S. Emerging Challenge of Mucormycosis in post COVID Patients. IAR J. Med. Case Rep. 2021, 2, 7-10.

13. Di Cosola, M.; Cazzolla, A.P.; Charitos, I.A.; Ballini, A.; Inchingolo, F.; Santacroce, L. Candida albicans and Oral Carcinogenesis. A Brief Review. J. Fungi 2021, 7, 476. [CrossRef]

14. Mandujano-González, V.; Villa-Tanaca, L.; Anducho-Reyes, M.A.; Mercado-Flores, Y. Secreted fungal aspartic proteases: A review. Rev. Iberoam. Micol. 2016, 33, 76-82. [CrossRef]

15. Adams, R.P. Identification of Essential oil Components by Gas Chromatography/Mass Spectrometry, 4th ed.; Allured Publ. Corp.: Carol Stream, IL, USA, 2007; pp. 1-804.

16. Pereira, A.Q.; Chaves, F.C.; Pinto, S.C.; Leitão, S.G.; Bizzo, H.R. Isolation and Identification of cis-7-Hydroxycalamenene from the Essential Oil of Croton cajucara Benth. J. Essent. Oil Res. 2011, 23, 20-23. [CrossRef]

17. De Siqueira, L.B.D.O.; dos Santos Matos, A.P.; da Silva Cardoso, V.; Villanova, J.C.O.; Guimarães, B.D.C.L.R.; Dos Santos, E.P.; Vermelho, A.B.; Santos-Oliveira, R.; Junior, E.R. Clove oil nanoemulsion showed potent inhibitory effect against Candida spp. Nanotechnology 2019, 30, 425101. [CrossRef]

18. Clinical and Laboratory Standards Institute (CLSI). Reference Method for Broth Dilution Antifungal Susceptibility Testing of Yeasts; Approved Standard M27-A2; National Committee for Clinical Laboratory Standards: Wayne, NJ, USA, 2002; pp. 1-51.

19. Clinical and Laboratory Standards Institute (CLSI). Reference Method for Broth Dilution Antifungal Susceptibility Testing of Filamentous Fungi; Approved Standard M38-A2; National Committee for Clinical Laboratory Standards: Wayne, NJ, USA, 2008 ; pp. 1-52.

20. Almeida, C.A.; Azevedo, M.; Chaves, F.; Roseo de Oliveira, M.; Rodrigues, I.A.; Bizzo, H.R.; Gama, P.E.; Alviano, D.S.; Alviano, C.S. Piper essential oils inhibit Rhizopus oryzae growth, biofilm formation, and rhizopuspepsin activity. Can. J. Infect. Dis. Med. Microbiol. 2018, 2018, 5295619. [CrossRef]

21. Löfgren, S.E.; Miletti, L.C.; Steindel, M.; Bachere, E.; Barracco, M.A. Trypanocidal and leishmanicidal activities of different antimicrobial peptides (AMPs) isolated from aquatic animals. Exp. Parasitol. 2008, 118, 197-202. [CrossRef]

22. Shinde, Y.B.; Kore, S. A Review on Mucormycosis with recent pharmacological treatment. J. Drug Deliv. Ther. 2021, 11, 145-149. [CrossRef]

23. Mahmoud, H.; Mohamed, N.T.; Abd-El-Sayed, M.A. Fungicidal Activity of Nanoemulsified Essential Oils Against Botrytis Leaf Blight of Poinsettia (Euphorbia pulcherrima) in Egypt. Egypt. J. Agric. Res. 2018, 96, 1259-1273.

24. Priyadarshini, K.A.; Murugan, K.; Panneerselvam, C.; Ponarulselvam, S.; Hwang, J.S.; Nicoletti, M. Biolarvicidal and pupicidal potential of silver nanoparticles synthesized using Euphorbia hirta against Anopheles stephensi Liston (Diptera: Culicidae). Parasitol. Res. 2012, 111, 997-1006. [CrossRef] [PubMed]

25. Javanshir, A.; Karimi, E.; Maragheh, A.D.; Tabrizi, M.H. The antioxidant and anticancer potential of Ricinus communis L. essential oil nanoemulsions. J. Food Meas. Charact. 2020, 14, 1356-1365. [CrossRef]

26. Zhu, Q.; Jiang, M.L.; Shao, F.; Ma, G.Q.; Shi, Q.; Liu, R.H. Chemical Composition and Antimicrobial Activity of the Essential Oil from Euphorbia helioscopia L. Nat. Prod. Commun. 2020, 15, 1934578X20953249. [CrossRef]

27. Azevedo, M.M.; Almeida, C.A.; Chaves, F.C.; Rodrigues, I.A.; Bizzo, H.R.; Alviano, C.S.; Alviano, D.S. 7-hydroxycalamenene effects on secreted aspartic proteases activity and biofilm formation of Candida spp. Pharmacogn. Mag. 2016, 12, 36. [CrossRef] [PubMed]

28. Rodríguez-Chávez, J.L.; Coballase-Urrutia, E.; Nieto-Camacho, A.; Delgado-Lamas, G. Antioxidant capacity of "Mexican arnica” Heterotheca inuloides Cass natural products and some derivatives: Their anti-inflammatory evaluation and effect on C. elegans life span. Oxid. Med. Cell. Longev. 2015, 2015, 843237. [CrossRef] [PubMed]

29. Yen, P.L.; Cheng, S.S.; Wei, C.C.; Lin, H.Y.; Liao, V.H.C.; Chang, S.T. Antioxidant Activities and Reduced Amyloid- $\beta$ Toxicity of 7-Hydroxycalamenene Isolated from the Essential Oil of Zelkova serrata Heartwood. Nat. Prod. Commun. 2016, 11, 1934578X1601100943. [CrossRef]

30. Bhadra, A.; Ahmed, M.S.; Rahman, M.A.; Islam, S. Mucormycosis or black fungus: An emerging threat in COVID-19. Bangabandhu Sheikh Mujib Med. Univ. J. 2021, 14, 51-56. [CrossRef]

31. Ezeokoli, O.T.; Gcilitshana, O.; Pohl, C.H. Risk factors for fungal co-infections in critically ill COVID-19 patients, with a focus on immunosuppressants. J. Fungi 2021, 7, 545. [CrossRef] 
32. Santos, A.L.S.D. Aspartic proteases of human pathogenic fungi are prospective targets for the generation of novel and effective antifungal inhibitors. Curr. Enzym. Inhib. 2011, 7, 96-118. [CrossRef]

33. Morace, G.; Borghi, E. Invasive mold infections: Virulence and pathogenesis of Mucorales. Int. J. Microbiol. 2012, $2012,349278$. [CrossRef]

34. Challa, S. Mucormycosis: Pathogenesis and Pathology. Curr. Fungal Infect. Rep. 2019, 13, 11-20. [CrossRef] 